\title{
Mechanistic Insights into the Decarboxylation of Oxaloacetate Catalyzed by Transition Metal Ions
}

\author{
Mingzhi Song ${ }^{a^{*}}$ and Chuangang Fan ${ }^{b}$ \\ Department of Chemical Engineering and Safety, Binzhou University, Binzhou, Shandong, 256603, \\ PR China \\ asongmingzhi2010@163.com, ${ }^{\text {f }}$ fanchuangang@163.com \\ *The Corresponding author
}

Keywords: Oxaloacetate; Decarboxylation mechanism; Transition metal; DFT

\begin{abstract}
The decarboxylation mechanism of oxaloacetate catalyzed by transition metal ions M( II) $(\mathrm{M}=\mathrm{Cu}, \mathrm{Zn}, \mathrm{Co}$ ) has been studied using Density Functional Theory (DFT). The calculations show that the catalytic cycle contains two stages: the formation of oxaloacetate-M( II ) complexes, and the cleavage of the $\mathrm{C}-\mathrm{C}$ bond, the latter one is the rate-determining step in the whole reaction. DFT studies suggest that there are two forms of oxaloacetate dianion, the enol and the keto, the energy barriers for the $\mathrm{C}-\mathrm{C}$ bond cleavage of the three oxaloacetate(enol)-M( II ) complexes are $89.5(\mathrm{Cu})$, $261.5(\mathrm{Zn})$, and $37.5(\mathrm{Co}) \mathrm{kJ} / \mathrm{mol}$, and the energy barrier for the keto form of oxaloacetate-M( II ) complexes are $25.3(\mathrm{Cu}), 31.2(\mathrm{Zn})$ and $63.3(\mathrm{Co}) \mathrm{kJ} / \mathrm{mol}$, respectively. The results investigate that the keto form of the oxaloacetate-M( II ) complexes is easily than the enol form, and Cu( II) has better catalytic activity than the other two metal ions.
\end{abstract}

\section{Introduction}

Essentially all of the carbon dioxide generated in fermentation and respiration is produced by decarboxylation of organic acids[1]. Therefore, decarboxylation is a process of widespread occurrence in nature and is of fundamental biological importance. A variety of mechanisms have been employed in biological systems to specifically decarboxylate substrate olecules[2-6]. Oxaloacetic $\operatorname{acid}(\mathrm{OAA})$ is a $\beta$-keto acid, it plays a central role in several metabolic pathways such as the tricarboxylic acid cycle, gluconeogenesis, fatty acid biosynthesis, amino acid degradation, and amino acid biosynthesis[7-11]. The $\beta$-Decarboxylation of oxaloacetate(OA) can be catalyzed by a number of agents including amines[12-15], enzymes[16-22], et al. Since Krampitz \& Werkman reported that $\mathrm{Mg}$ ( II ) can accelerate the decomposition of oxaloacetate[23], many metal ions catalyzed decarboxylation of oxaloacetic acid have been studied[24-36], a number of multivalent cations $(\mathrm{Cu}$ ( II ), $\mathrm{Fe}$ ( II ), $\mathrm{Co}$ ( II ), Ni( II ), Zn( II ), etc.) are shown have good catalytic activity in the ketone decarboxylation. The study of Ito's group[37] on "metal-ion catalyzed decarboxylation of oxaloacetic acid" show that the decarboxylation of oxaloacetic acid is accelerated when oxaloacetic acid chelates with divalent cation ions, the activation energy is reduced upon metal chelate formation. Then Leussing [38, 39] and Gregory[40] made some reports about $\mathrm{Cu}$ ( II ) and $\mathrm{Zn}$ ( II ) catalysis of oxalacetate enolization and decarboxylation, they observed that the ability of various metal ions to promote decarboxylation closely parallels the stabilities of their respective oxaloacetate complexes.

Studies on mechanistic aspects of the reaction are almost from experimental research and as we know that there is less research on theoretical calculation aspects. Here we report a machanistic study on metal ions catalyzed decarboxylation of OA using density functional theory, revealing the catalytic activity of several metal ions in the decarboxylation reaction.

\section{Computational Method}

All calculations were carried out using B3LYP functional theory[41]. Herein, the metal (copper, zinc, cobalt) atom was treated with the SDD relativistic effective core potential[42-43]. For $\mathrm{C}, \mathrm{H}$ and $\mathrm{O}$, the 
6-311+G (d, p) basis set was adopted. Geometries of the reactants, intermediates, transition states and products involving the decarboxylation reaction system of OA were fully optimized. Frequency calculations were performed to identify all the stationary points as minima (zero imaginary frequency) or transition states (one imaginary frequency), and provide zero-point vibration energy (ZPVE). The transition states were checked by intrinsic reaction coordinates (IRC) calculations to confirm their connections between the corresponding intermediates and products. The zero-point vibrational energy (ZPVE, 1/2Rhx1) scaling and the thermal correction (TC) were also carried out.

\section{Results and Discussion}

In this study, we first examined the coordination of OA with metal catalyst, followed by an investigation on the possible pathways. After that, careful comparisons of these pathways were performed to generate the most favorable one.

A $\mathrm{M}$ (II) $(\mathrm{M}=\mathrm{Cu}, \mathrm{Zn}, \mathrm{Co})$ catalytic cycle is proposed for the decarboxylative reaction for the enol-type and keto-type of OA in Scheme 1. While Figs. 1 and 2 display the optimized structures for relevant transition states and key intermediates. The free energy profiles are shown in Fig. 3.

According to the study of Ito[37], two possible pathways of the catalyzed decarboxylation are listed in Scheme 1. Firstly, OA (enol-type or keto-type) coordinated with the metal ion forming the organometallic complex, then the complex decarboxylated to generate the product-metal complex, finally the product complex decomposed. The calculation illustrates that the decarboxylation step is the rate-limiting one, so here we mainly discussed the catalyzed decarboxylation step.

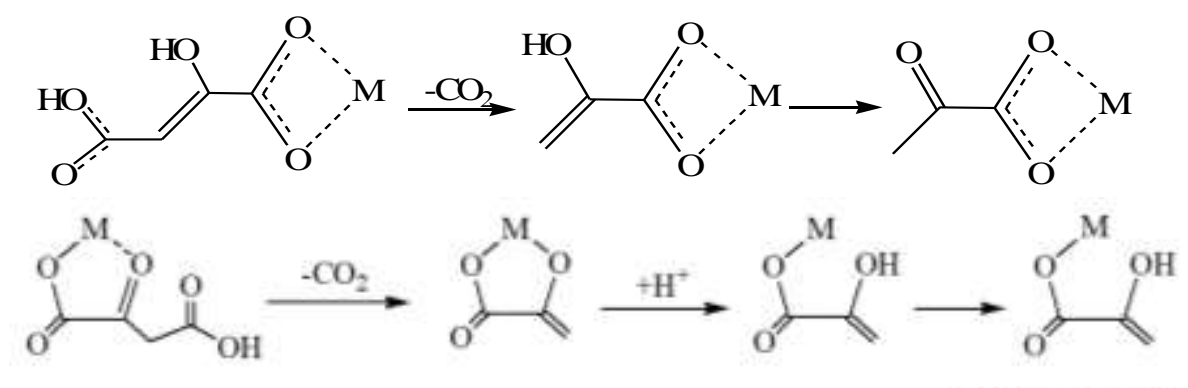

$(\mathrm{M}=\mathrm{Cu}, \mathrm{Zn}, \mathrm{Co})$

Scheme $1 \mathrm{M}(\mathrm{II})(\mathrm{M}=\mathrm{Cu}, \mathrm{Zn}, \mathrm{Co})$ catalytic decarboxylation mechanism of OA :

(1) enol-type, (2) keto-type

We firstly analyzed the catalyzed reaction of enol. Fig. 1 shows that the enol coordinate with the three transition metal ions to intermediate complex RA-M $(\mathrm{M}=\mathrm{Co}, \mathrm{Cu}, \mathrm{Zn})$. In RA-M, the metal ions coordinated with $\mathrm{O} 7$ and $\mathrm{O} 9$, generating a four-member-ring, and the bond lengths of the M-O7 are $2.109(\mathrm{Co}), 2.104(\mathrm{Cu})$, and $2.088 \AA(\mathrm{Zn})$, respectively. Then with the breaking of C2-C6 bond, the complex decarboxylated to form the product complex and carbon dioxide, the transition state structures are TSA-M $(\mathrm{M}=\mathrm{Co}, \mathrm{Cu}, \mathrm{Zn})$, in which the lengths of $\mathrm{C} 2-\mathrm{C} 6$ bonds enlarged from 1.457 $(\mathrm{Co}), 1.454(\mathrm{Cu})$, and $1.495 \AA(\mathrm{Zn})(\mathrm{RA}-\mathrm{M})$ to $2.071(\mathrm{Co}), 1.978(\mathrm{Cu})$, and $2.073 \AA(\mathrm{Zn})$, respectively. And the energy barriers are 37.5(Co), 89.5(Cu), 261.3(Zn) kJ/mol (Fig. 3(a)) for the decarboxylation, which indicates that $\mathrm{Co}$ (II) is the most favorite catalyst for the decarboxylation of enol. The total energetic profile illustrate that the three catalytic reactions are all exothermic ones, and the Gibbs free energy released are $101.4,87.5$, and $101.4 \mathrm{~kJ} / \mathrm{mol}$ for $\mathrm{RA}-\mathrm{M}(\mathrm{M}=\mathrm{Co}, \mathrm{Cu}, \mathrm{Zn})$ respectively.

Then the mechanism of the decarboxylation of the keto is discussed. The optimized structures of the reactant complexes (RB-M, M=Co, Cu, $\mathrm{Zn}$ ), transition states(TSB-M), and the products(P-M) are listed in Fig. 2. In RB-M, different with RA-M, the metal ions coordinated with $\mathrm{O} 4$ and $\mathrm{O} 7$, and a five-member-ring is generated. The bond lengths of the M-O4 are 2.089 (Co), 2.144(Cu), and $2.022 \AA$ $(\mathrm{Zn})$, respectively. Then same with RA-M, through the transition state TS-M, the C2-C6 bond is broken, and the product complexes PB-M are produced, releasing carbon dioxide. From RB-M to TS-M, the bond length of C2-C6 is enlarged from $1.523(\mathrm{Co}), 1.515(\mathrm{Cu})$, and $1.540 \AA$ ( $\mathrm{Zn})$ to 2.080 
(Co), $1.960(\mathrm{Cu})$, and $1.960 \AA \mathrm{Zn})$. Fig. 3(b) shows that the energy barriers are 63.3, 25.3, $31.2 \mathrm{~kJ} / \mathrm{mol}$ (Fig. 3(a)) for the decarboxylation of RB-M (M=Co, Cu, $\mathrm{Zn})$, indicating that $\mathrm{Cu}(\mathrm{II})$ is the most favorite catalyst for the reaction of Keto-type OA. Similar to enol, the three catalytic reactions are all exothermic, and the releasing Gibbs free energies are 269.5, 196.3, and 49.0 kJ/mol for RB-M (M=Co, $\mathrm{Cu}, \mathrm{Zn}$ ) respectively.

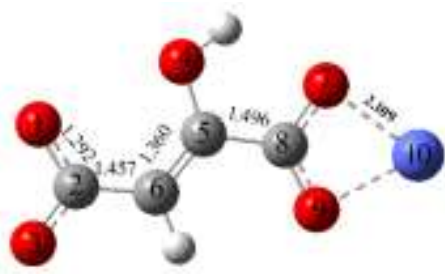

RA-Co

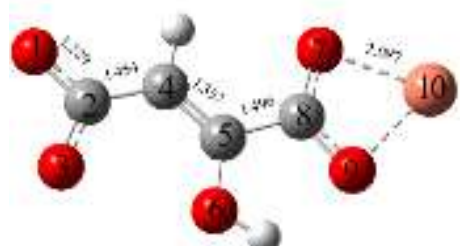

$\mathrm{RA}-\mathrm{Cu}$

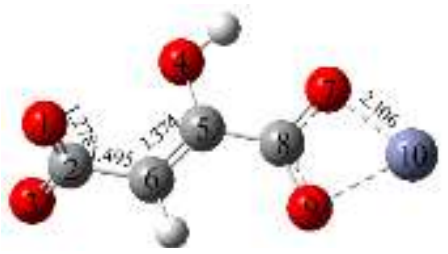

RA-Zn

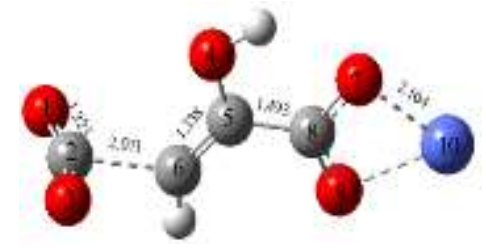

PA-Co

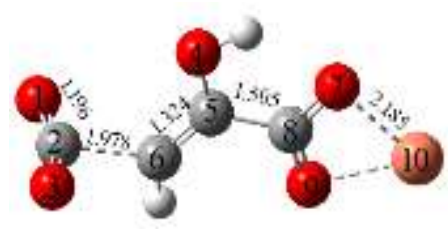

$\mathrm{PA}-\mathrm{Cu}$

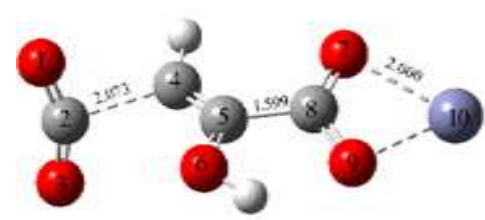

PA-Zn
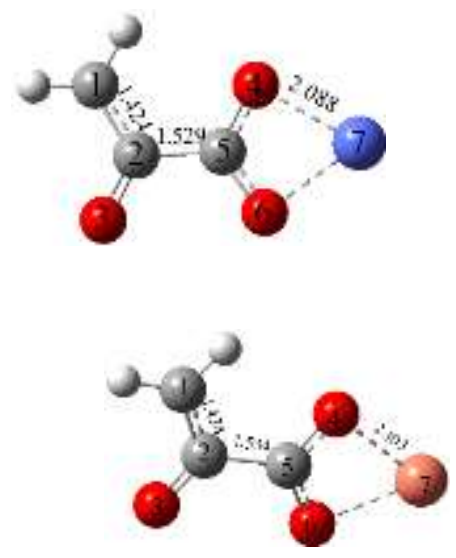

TSA-Cu

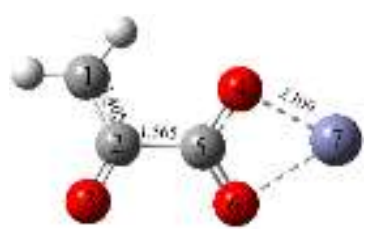

Figure 1. The structures of the intermediates and transition states in the metal-catalyzed decarboxylation of the enol-type of OA. (bond length: $\AA$ ) 


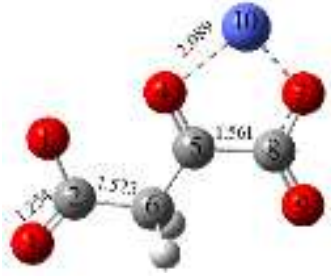

RB-Co

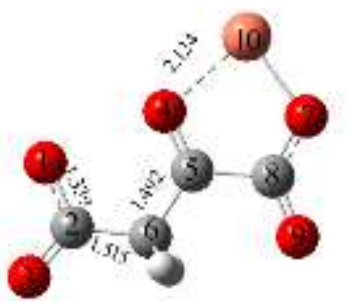

$\mathrm{RB}-\mathrm{Cu}$

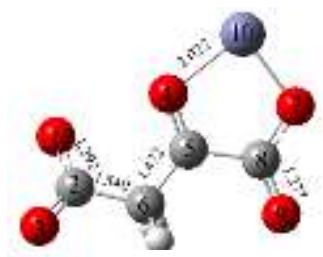

$\mathrm{RB}-\mathrm{Zn}$

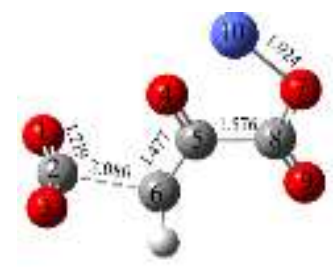

PB-Co

TSB-Co
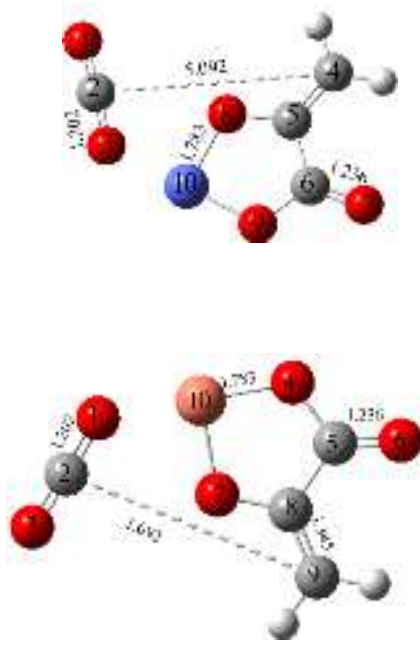

$\mathrm{TSB}-\mathrm{Cu}$

$\mathrm{PB}-\mathrm{Cu}$
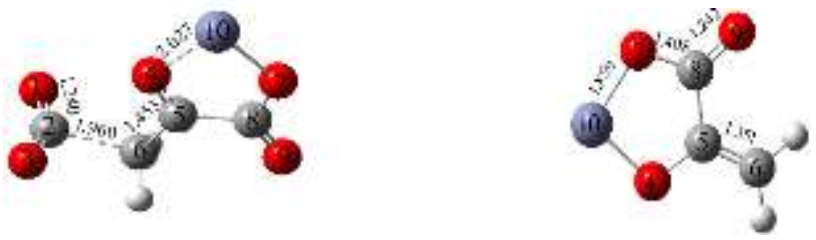

TSB-Zn

PB-Zn

Figure 2. The structures of the intermediates and transition states in the metal-catalyzed decarboxylation of the keto-type of OA. (bond length: $\AA$ )

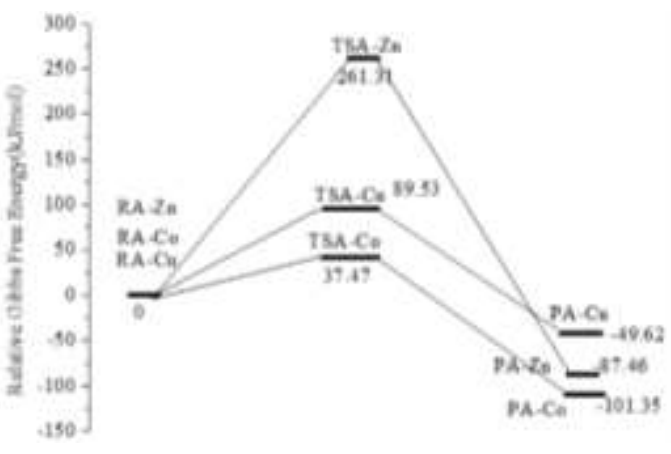

(a) enol-type

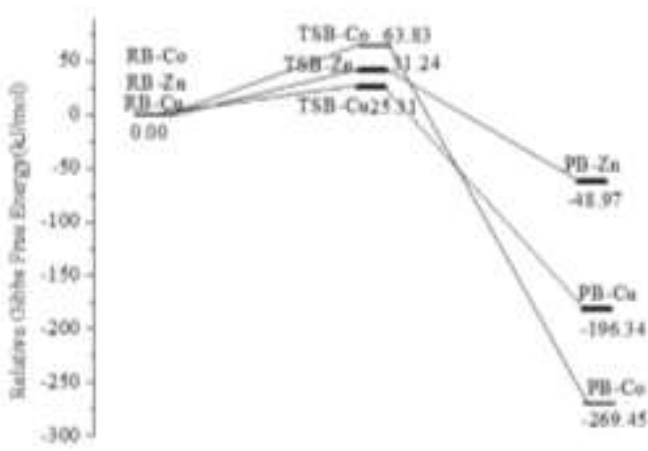

(b) keto-type

Figure 3. Energetic profiles for decarboxylation of OA catalyzed by metal ions (Co(II) $\mathrm{Cu}$ (II) $\mathrm{Zn}(\mathrm{II})$ ) at B3LYP/SDD level

From the above analysis we can find that, whether it's an enol or a ketone, the catalytic decarboxylation is exothermic, indicating that the reaction is beneficial in thermodynamics.

The above discussion also indicates that for the catalyst Co (II), the decarboxylation of enol is easier than the keto, and it has the best catalytic activity of the three transition metal ions in the reaction of enol-form of OA. While for $\mathrm{Cu}$ (II) or $\mathrm{Zn}$ (II), the decarboxylation of keto is much easier than the enol, and $\mathrm{Cu}$ (II) has the best catalytic activity. Comparing the activation energy of the two reaction pathways, it can be found that the decarboxylation of ketone is easier than enol, which is assistant with the study of Leussing[39]. 


\section{Conclusions}

Transition metal ions catalyzed-decarboxylation mechanism of oxaloacetate has been studied using Density Functional Theory (DFT). Two possible pathways of the catalyzed decarboxylation have been discussed. The calculations show that the catalytic decarboxylation of OA is exothermic whether it's an enol or a ketone. And from a dynamics point of view, the energy barriers for the $\mathrm{C}$ - $\mathrm{C}$ bond cleavage of the three oxaloacetate(enol)-M( II ) complexes (enol)-M( II ) complexes are respectively $89.5(\mathrm{Cu}), 261.5(\mathrm{Zn})$, and $37.5(\mathrm{Co}) \mathrm{kJ} / \mathrm{mol}$, and the energy barrier for the keto form of oxaloacetate-M( II ) complexes are 25.3(Cu), 31.2(Zn) and 63.3(Co) $\mathrm{kJ} / \mathrm{mol}$, respectively, showing that the keto form of the oxaloacetate-M( II ) complexes is easily than the enol form, and $\mathrm{Cu}$ ( II ) has better catalytic activity than other two metal ions.

\section{Acknowledgements}

This work was financially supported by the Binzhou University Research Fundation (projects no. 2014Y05).

\section{References}

[1] S. Ochoa: Physiol. Rev., Vol. 56 (1951), p.56.

[2] S.M. Sullivan and T. Holyoak: Biochemistry, Vol. 46 (2007), p.10078.

[3] M. Balsera, R.M. Buey and X.D. Li: J. Biol. Chem., Vol. 286 (2011), p.9457.

[4] A. Brik, L.J. D'Souza, and E. Keinan: Chem. Bio. Chem., Vol. 3 (2002), p.845.

[5] A.D. Lietzan and M.S. Maurice: Archives of biochemistry and biophysics, Vol. 544 (2014), p.75.

[6] H.M. Wilkins, S. Koppel, S.M. Carl, S. Ramanujan, I. Weidling, M.L. Michaelis and E.K. Michaelis: Journal of Neurochemistry, Vol. 137 (2016), p.76.

[7] V.T. Turkelson and M. Richards: Analytical Chemistry, Vol. 50 (1978), p.1421.

[8] F. Tanaka, R. Fuller and C.F. Barbas: Biochemistry, Vol. 44 (2005), p.7583.

[9] S.M. Sullivan and T. Holyoak: Biochemistry, Vol. 46(2007), p.10078.

[10] J.M. Serafimov, D. Gillingham, S. Kuster and D. Hilvert: J. Am. Chem. Soc. Vol. 130 (2008), p.7798.

[11] M. Asim, S. Jiang, L. Yi, W. Chen, L. Sun, L. Zhao and M. NasirKhan: Virus Research, Vol. 227 (2017), p.245.

[12] D.L. Leussing and N.V. Raghavan: J. Am. Chem. Soc., Vol. 102(1980) No. 17, p.5635.

[13] K. Ogino, H. Azuma, and H. Tamiya: J. Chem. Soc., Perkin Trans. 2, (1996), p.2005.

[14] K. Ogino, H. Tamiya and Y. Kimura: J. Chem. Soc., Perkin Trans. 2, (1996), p.979.

[15] N.K. Thalji, W.E. Crowe and G.L. Waldrop: J. Org. Chem., Vol. 74 (2009) No. 1, p.144.

[16] S. Seltzer, G.A. Hamilton and F.H. Westheimer: J. Am. Chem. Soc., Vol. 81 (1959), p.4018.

[17] I. Fridovich, F.H. Westheimer: J. Am. Chem. Soc., Vol.84 (1962), p.3208.

[18] G.W. Kosickit: Biochemistry, Vol. 7 (1968), p.4310.

[19] (a) G.L. Waldrop, B.F. Braxton, J.L. Urbauer, W.W. Cleland and D.M. Kiick: Biochemistry, Vol. 33 (1994), p.5262. (b) M.S. Jetten and A.J. Sinskey: Antonie Van Leeuwenhoek, Vol. 67 (1995), p.221. (c) N.E.L. Abrou and Y.D. Clonis: Arch. Biochem. Biophys., Vol. 365 (1999), p.17.

[20] A. Liu and H. Zhang: Biochemistry, Vol. 46 (2007), p.10078.

[21] S. Wang, D. Tholen and X. Zhu: Plant Cell \& Environment, Vol. 40 (2017), p.80.

[22] L.O. Krampitz and C.H. Werkman: Biochemical Journal, Vol. 35 (1941) Nos.5-6, p.595.

[23] R. Steinberger and F.H. Westheimer: J. Am. Chem. Soc., Vol. 73 (1951), p.429.

[24] K.J. Pedersen: Acta Chemica Scandinavica, Vol. 6 (1952), p.285.

[25] (a) E. Gelles: Nature, Vol. 176 (1955), p.925. (b) E. Gelles and K.S. Pitzer: J. Am. Chem. Soc., Vol. 77 (1955), p.1974.

[26] G.W. Kosicki and S.N. Lipovac: Nature, Vol. 200 (1963), p.359.

[27] K.G. Claus and J.V. Rund: Inorg. Chem., Vol. 8 (1969), p.59. 
[28] M. Birus and D.L. Leussing: Inorg. Chem., Vol. 21 (1982), p.374.

[29] C.B. Grissom and W.W. Cleland: J. Am. Chem. Soc., Vol. 108 (1986), p.5582.

[30] C.B. Monk: J. Chem. Soc., Dalton Trans., (1991), p.1479.

[31] T. Holyoak, S.M. Sullivan and T. Nowak: Biochemistry, Vol. 45 (2006), p.8254.

[32] J. Cheung, M.E.P. Murphy and D.E. Heinrichs: Chemistry \& Biology, Vol. 19 (2012) p.1568.

[33] R. Stark and R.G. Kibbey: Biochimica et Biophysica Acta, Vol. 1840 (2014), p.1313.

[34] E. Camprubi, S.F. Jordan, R. Vasiliadou and N. Lane: IUBMB Life, Vol. 69 (2017), p.373.

[35] W.A. Jefferson, C. Hu, D. Song, H. He and J. Qu: ACS Omega, Vol. 2 (2017), p.6728.

[36] H. Ito, H. Kobayashi and K. Nomiya: Journal of the Chemical Society, Faraday Transactions 1: Physical Chemistry in Condensed Phases, Vol. 69 (1973), p.113.

[37] W.D. Covey and D.L. Leussing: Journal of the American Chemical Society, Vol. 96 (1974) No.12, p.3860.

[38] N.V. Raghavan and D.L. Leussing: Journal of the American Chemical Society, Vol. 98 (1976) No. 3, p.723.

[39] G. Kubala, A.E. Martell: Journal of the American Chemical Society, Vol. 104 (1982) No. 24, p.6602

[40] C. Lee, W. Yong and R.G. Pan: Phys. Rev., Vol. B37 (1988), p.785.

[41] M. Dolg, U. Wedig, H. Stoll and H. Preuss: J Chem. Phys., Vol. 86 (1987), p.866.

[42] D. Andrae, U. Haüßermann, M. Dolg, H. Stoll and H. Preuss: Theor Chem Acc, Vol. 77 (1990), p.123.

[42] Peng L, Xiaoping Z. Social Stratification and Cooperative Behavior in Spatial Prisoners'

Dilemma Games [J]. PLOS ONE, 2015, 10(7):e0131005. 